\title{
LA PROTECCIÓN DE LA LIBERTAD DE CULTO EN TIEMPOS DE PANDEMIA: LA JURISPRUDENCIA DE LA CORTE DE APELACIONES DE CONCEPCIÓN. COMENTARIO A LAS SENTENCIAS 7800-2020, 9692-2020 Y 11125-2020.
}

\author{
[Protection of freedom to worship in the pandemic: the case law of the \\ Appeals Court of Concepción. Analysis to the following cases 7800-2020, \\ 9692-2020 and 11125-2020]
}

MACARENA BUSTAMANTE SINN ${ }^{1}$

ROBERTO ASTABURUAGA BRISEÑO²

\begin{abstract}
Resumen
El comentario analiza tres sentencias dictadas por la Corte de Apelaciones de Concepción, una de ellas confirmada por la Corte Suprema, sobre la afectación al ejercicio de la libertad de culto por la dictación de medidas sanitarias para frenar el contagio y propagación del Covid-19, analizando la evolución en el conocimiento y resolución de los recursos interpuestos.

Palabras clave: Libertad de culto, restricción, suspensión, medidas sanitarias, Covid-19.

Abstract

The commentary analyzes three sentences handed down by the Concepción Court of Appeals, one of them confirmed by the Supreme Court concerning the impact on the exercise of worship freedom by the issuance of sanitary measures to stop the contagion and spread of Covid-19, analyzing the evolution in knowledge and resolution of the filed appeals.
\end{abstract}

Key words: Freedom of worship, restriction, suspension.

DOI: $10.7764 / R L D R .10 .130$

\footnotetext{
${ }^{1}$ Abogado Área Judicial, Corporación Comunidad y Justicia, mbustamante@comunidadyjusticia.cl

${ }^{2}$ Abogado Área Judicial, Corporación Comunidad y Justicia, rastaburuaga@comunidadyjusticia.cl
} 
Macarena Bustamante y Roberto Astaburuaga: La protección de la libertad de culto en tiempos de pandemia: la jurisprudencia de la corte de apelaciones de concepción. Comentario a las sentencias 7800-2020, 9692-2020 y $11125-2020$.

\section{INTRODUCCIÓN}

Poco después de que el Covid-19 fuese decretado como "pandemia" por la OMS, el Presidente de la República de Chile decidió decretar Estado de Excepción Constitucional en el país, cuestión que tuvo lugar el 18 de marzo de 2020. A partir de esa fecha, las autoridades estatales han tomado una serie de medidas tendientes a evitar el contagio y propagación de esta enfermedad. Éstas se han manifestado principalmente por medio de Resoluciones Exentas, tanto del Ministerio de Salud, como de las Secretarías Regionales respectivas, que fueron dictadas en ejercicio de las facultades extraordinarias conferidas por el estado de Alerta Sanitaria.

Sin embargo, dichas medidas no han estado exentas de polémica, toda vez que su aplicación ha significado en ocasiones, la vulneración ilegítima de derechos protegidos constitucionalmente. En el presente caso, la normativa dictada por la autoridad sanitaria constituyó una afectación al contenido esencial de la libertad de culto, razón por la cual fue necesario acudir a los tribunales de justicia para solicitar que se restableciese el imperio del derecho.

\section{ANTECEDENTES}

Con fecha 30 de enero de 2020, el Director General de la Organización Mundial de la Salud- en adelante OMS-, declaró que el brote de Covid-19 constituye una Emergencia de Salud Pública de Importancia Internacional (ESPII), de conformidad a lo dispuesto en el artículo 12 del Reglamento Sanitario Internacional.

En Chile, ante esta grave situación, el 8 de febrero de 2020, el Ministerio de Salud dictó el Decreto № 4, que “decreta Alerta Sanitaria por el período que se señala y otorga 
Macarena Bustamante y Roberto Astaburuaga: La protección de la libertad de culto en tiempos de pandemia: la jurisprudencia de la corte de apelaciones de concepción. Comentario a las sentencias 7800-2020, 9692-2020 y $11125-2020$.

facultades extraordinarias que indica por Emergencia de Salud Pública de Importancia Internacional (ESPII) por brote del nuevo coronavirus (2019-NCOV)". En tal decreto, se le entregaron facultades extraordinarias tanto al Ministerio de Salud, como a los organismos que dependen de él. Por tanto, cada una de las Secretarías Regionales Ministeriales de Salud - en adelante, "Seremis de Salud"- quedaron facultadas por todo el tiempo que durara la emergencia sanitaria, para adoptar distintas medidas orientadas a prevenir el contagio y propagación del Covid-19 como, por ejemplo, la prohibición de funcionamiento de los establecimientos y lugares de trabajo que pongan en peligro a las personas que trabajan o asisten a ellos, entre otras.

Con fecha 18 de marzo de 2020, el Presidente de la República declaró el Estado de Excepción Constitucional de Catástrofe, por calamidad pública, en el territorio de Chile, a través del Decreto Supremo № 104, de 2020, del Ministerio del Interior y Seguridad Pública. Así, el artículo 4을 de dicho decreto dispone que, para el ejercicio de las facultades que ahí se entregan, "los Jefes de la Defensa Nacional deberán tomar en consideración las medidas sanitarias dispuestas para evitar la propagación del Covid-19, en actos administrativos dictados por el Ministro de Salud.", teniendo la facultad de controlar la entrada y salida de la zona declarada en estado de catástrofe y el tránsito en ella y establecer condiciones para la celebración de reuniones en lugares de uso público, entre otras. Además, dicho estado de excepción constitucional permite restringir las libertades de locomoción y de reunión, disponer requisiciones de bienes, establecer limitaciones al ejercicio del derecho de propiedad y adoptar todas las medidas extraordinarias de carácter administrativo necesarias para el restablecimiento de la normalidad en la zona afectada ${ }^{3}$.

El 4 de mayo de 2020, el Ministerio de Salud dictó el Decreto Supremo № 18, publicado en el Diario Oficial el 14 del mismo mes, modificando el Decreto $\mathrm{N}^{\circ} 4$ del mismo

\footnotetext{
${ }^{3}$ Existen dos límites: (1) las medidas que limitan o suspende alguno de los derecho señalados, no entrañen discriminación alguna fundada en motivos de raza, color, sexo, idioma, religión u origen social, y (2) en ningún caso pueden verse suspendidos, ya sea directa o indirectamente, ciertos derechos esenciales, señalados en el artículo 27 inciso segundo de la Convención Americana de Derechos Humanos (el derecho a la vida, a la integridad personal, el principio de legalidad, el derecho a la libertad de conciencia y religión, así como las garantías judiciales indispensables para la protección de tales derechos).
} 
Macarena Bustamante y Roberto Astaburuaga: La protección de la libertad de culto en tiempos de pandemia: la jurisprudencia de la corte de apelaciones de concepción. Comentario a las sentencias 7800-2020, 9692-2020 y $11125-2020$.

Ministerio. En él, se permitía a las autoridades, delegar funciones en otros funcionarios, otorgándoles, además, ciertas facultades extraordinarias. De este modo, a través de Resoluciones Exentas, el Ministerio de Salud, impuso medidas tendientes a evitar la propagación de esta enfermedad, tales como el establecimiento de cuarentenas para distintas comunas del país; la prohibición de concentración de más de 50 personas en un lugar determinado (independiente de su naturaleza, sea un espacio abierto o cerrado) ${ }^{4}$; la implementación de cordones sanitarios; la obligación de usar mascarillas ${ }^{5}$; el cierre de establecimientos como gimnasios, cines, teatros, pubs, etc ${ }^{6} ;$ u otras medidas según las tasas de contagio de cada comuna y Región.

Sin embargo, ciertas Seremis de Salud, excediendo sus atribuciones, ordenaron medidas que afectaban de manera ilegítima, derechos garantizados constitucionalmente, como fue el caso de la libertad de culto ${ }^{7}$. Particularmente en la VIII Región del Bío Bio, se

${ }^{4}$ Cfr. Resolución Exenta №341 del Ministerio de Salud, 13 de mayo de 2020, №28.

${ }^{5}$ Ibíd., N ${ }^{\circ} 24-27$.

${ }^{6}$ Cfr. Resolución Exenta N³49 del Ministerio de Salud, 15 de mayo de 2020.

7 - Resolución Exenta N8804, de la Seremi de Salud de la XVI Región del Ñuble, 24 de marzo de 2020: "1.DISPONGASE en la Región de Ñuble la prohibición de celebrar actividades deportivas culturales, religiosas, sean estas que se desarrollen en espacios abiertos como cerrados y que constituyan aglomeración de personas. 2.Dispóngase en la Región de Nuble la restricción del ingreso a instalaciones comerciales de acceso al público que no superen una persona por metro cuadrado, correspondiendo a los responsables de dichos locales o sus representantes legales, velar por el cumplimiento de dicha medida sanitaria de emergencia, resguardando siempre la distancia señalada entre clientes. Además, todos los locales de acceso al público deberán contar con elementos de sanitización y/o higienización de manos en los ingresos de éstos. 3.- Dichas medidas sanitarias tendrán una vigencia por todo el tiempo que dure la alerta sanitaria y estado de Excepción Constitucional de Catástrofe por Calamidad Pública hasta que no se disponga lo contrario".

- Resolución Exenta N 726 de la Seremi de Salud de la VII Región del Maule, 24 de marzo de 2020: "Primero: Prohíbase el aforo o reunión de personas con motivo de celebraciones religiosas que se desarrollen en la vía pública o lugares privados, incluyendo centros cívicos, sociales, deportivos o asimilables. Esta medida comenzará a regir desde las 00:00 del 25 de marzo de 2020 y será aplicada por un plazo indefinido, hasta que las condiciones epidemiológicas permitan su supresión".

- Resolución Exenta N 988 de la Seremi de Salud de la VI Región del Libertador General Bernardo O’Higgins, del 23 de marzo de 2020: "Primero: Establézcase la medida de limitar la cantidad de asistentes a todo tipo de actividades, ceremonias o ritos religiosos en espacios abiertos o cerrados, en la Región del Libertador General Bernardo O'Higgins, hasta aquella cantidad que permita mantener una distancia de un metro y medio entre personas. Segundo: Déjase establecido que la anterior medida será aplicable a las iglesias, confesiones e instituciones religiosas de cualquier culto, siendo responsable de su implementación el representante de cada institución religiosa, de acuerdo con sus respectivos estatutos o normativa aplicable. Tercero: Déjase establecido que la anterior medida se extenderá, además, a todo recinto abierto o cerrado en el cual se practiquen o realicen exequias u honras fúnebres". 
Macarena Bustamante y Roberto Astaburuaga: La protección de la libertad de culto en tiempos de pandemia: la jurisprudencia de la corte de apelaciones de concepción. Comentario a las sentencias 7800-2020, 9692-2020 y $11125-2020$.

dictaron una serie de Resoluciones Exentas sobre esta materia, las que tienen relación con los distintos procesos y sentencias que serán comentadas a continuación.

\section{PROCESOS Y SENTENCIAS}

\section{SENTENCIA DE LA CORTE DE APELACIONES DE CONCEPCIÓN DE FECHA 07 DE ABRIL DE 2020, ROL 7800-2020, CONFIRMADA POR SENTENCIA DE LA EXCMA. CORTE SUPREMA, DE FECHA 24 DE ABRIL DE 2020, ROL N $42853-2020$.}

El inicio de la controversia que originó este proceso tuvo lugar cuando la Seremi de Salud de la Región del Bío Bio ordenó con fecha 29 de marzo la clausura y prohibición de funcionamiento de la Catedral de la ciudad de Los Ángeles y de otras iglesias católicas, todas de la misma Región, luego de constatar que en ellas se continuaba celebrando la Santa Misa (aun cuando dichas ceremonias cumplían con todas las medidas sanitarias pertinentes).

El fundamento de derecho de dicha decisión fue lo dispuesto en la Resolución Exenta N¹094, dictada el 23 de marzo de 2020: “1.- Dispóngase en la Región del Bio Bío, la prohibición de celebrar actividades deportivas, culturales, religiosas, sean éstas que se desarrollen en espacios abiertos, como cerrados y que constituyan aglomeración de personas. 2.- Dispóngase en la Región del Bio Bío la restricción del ingreso a instalaciones comerciales de un número que no supere las 50 personas, correspondiendo a los responsables de dichos locales o sus representantes legales velar por el cumplimiento de dicha medida sanitaria de emergencia. 3.- Dichas medidas sanitarias tendrán una vigencia por todo el tiempo que dure la alerta sanitaria y Estado de Excepción Constitucional de Catástrofe por Calamidad Pública, hasta que no se disponga lo contrario".

\footnotetext{
- Resolución Exenta № 232 de la Seremi de Salud de la XI Región de Aysén, 24 de marzo de 2020: “Prohíbase la realización de todo acto, celebración, ceremonial, ceremonia, misa, liturgia o cualquiera sea la denominación que se le aplique, de carácter religioso que implique aglomeración de personas, desde esta fecha y hasta que el riesgo de propagación de la pandemia sea superado (...)".
} 
Macarena Bustamante y Roberto Astaburuaga: La protección de la libertad de culto en tiempos de pandemia: la jurisprudencia de la corte de apelaciones de concepción. Comentario a las sentencias 7800-2020, 9692-2020 y $11125-2020$.

Ante esto, un grupo de laicos católicos interpuso un recurso de protección ante la Corte de Apelaciones de Concepción, en contra de la Seremi de Salud de la Región del Bío Bio, para que fueran dejadas sin efecto tanto la Resolución N¹094 como el acta de clausura de las iglesias católicas. Sin embargo, el recurso de protección fue declarado inadmisible por la Corte, frente a lo cual los recurrentes interpusieron un recurso de reposición con apelación en subsidio, siendo el primero rechazado y llegando así el asunto al conocimiento de la Corte Suprema. Sin embargo, ésta confirmó la decisión de la Corte de Apelaciones de declarar inadmisible la acción de protección intentada.

Respecto de lo anterior, la Corte de Apelaciones de Concepción, al negar la admisibilidad del recurso, señaló que: “Atendido el mérito de los antecedentes, estimando esta Corte que lo solicitado en el recurso de protección no dice relación con cautelar el respeto y ejercicio de garantías constitucionalmente protegidas, sino que se vincula con la adopción de estrategias propias de la determinación de políticas públicas para hacer frente a la afectación sanitaria que aqueja al país, gestión que es privativa del Ejecutivo y que no corresponde a los Tribunales de Justicia establecer, excediendo la petición en análisis los fines y propósitos de este arbitrio excepcional y de urgencia y visto lo dispuesto en el numeral 2 del Auto Acordado de la Excma. Corte Suprema, se declara INADMISIBLE el recurso de protección interpuesto" 8 .

Por su parte, la Corte Suprema, al rechazar el recurso de apelación relativo a la admisibilidad, indicó: "Vistos, y teniendo además presente, que el inciso $2^{\circ}$ del artículo 19 N 6 de la Constitución Política señala: "Las confesiones religiosas podrán erigir y conservar templos y sus dependencias bajo las condiciones de seguridad e higiene fijadas por las leyes y ordenanzas", se confirma la resolución apelada de fecha siete de abril de dos mil veinte, dictada por la Corte de Apelaciones de Concepción”9.

\footnotetext{
${ }^{8}$ Ilustrísima Corte de Apelaciones de Concepción, Rol N. 7800-2020, sentencia definitiva,7 de abril de 2020.

${ }^{9}$ Excelentísima Corte Suprema, Rol No. 42.853-2020, sentencia definitiva, 24 de abril de 2020.
} 
Macarena Bustamante y Roberto Astaburuaga: La protección de la libertad de culto en tiempos de pandemia: la jurisprudencia de la corte de apelaciones de concepción. Comentario a las sentencias 7800-2020, 9692-2020 y $11125-2020$.

\section{SENTENCIA DE LA CORTE DE APELACIONES DE CONCEPCIÓN, DEL 22 DE JULIO DE 2020, ROL N $9692-2020$.}

Como ya se señaló en el punto III.1, la Seremi de Salud del Bío Bio dictó con fecha 23 de marzo la Resolución Exenta №1094, que prohibía la celebración de actividades religiosas, sea que se desarrollen en espacios abiertos como cerrados y que constituyesen aglomeración de personas. No obstante, con fecha 5 de mayo, dictó la Resolución Exenta №1059, por medio de la cual revocó dicha medida sanitaria, en la parte que prohibía la celebración de actividades religiosas. El fundamento de esta nueva medida fue -como se señala expresamente- "preservar la libertad de culto"; estableciendo eso sí, ciertas medidas sanitarias. Así, este nuevo acto administrativo disponía lo siguiente: "1.- DECRETESE el alzamiento de la medida sanitaria de prohibición de celebrar actividades religiosas en recintos abiertos como cerrados decretada por esta Autoridad Administrativa mediante Resolución Exenta Nº 1094 de fecha 23.03.2020. 2.- DEJESE SIN EFECTO la Resolución Exenta Nº 1094 de fecha 23.03.2020 del Seremi de Salud solo en cuanto a la prohibición de celebrar actividades religiosas en recintos abiertos como cerrados".

Sin embargo, la dictación de la Resolución N¹509, con la consecuente alza de la prohibición de celebrar actividades religiosas, trajo como consecuencia que uno de los concejales de la comuna de Chiguayante- ubicada también en la VIII Región-, interpusiera una acción de protección constitucional, esta vez con el objeto de que se mantuviese la prohibición de celebración de actividades religiosas a fin de proteger la vida y la salud de los "chiguayantinos".

La acción interpuesta por el concejal ya referido fue presentada con fecha 8 de mayo de 2020, en contra, como ya señalamos, de la Resolución Exenta N¹509. Sin embargo, un día antes, el 7 de mayo, la Seremi de Salud había dictado una nueva Resolución, la N¹529, que dejaba sin efecto, en su totalidad, las Resoluciones Exentas № 1094 y 1509, y ordenaba 
Macarena Bustamante y Roberto Astaburuaga: La protección de la libertad de culto en tiempos de pandemia: la jurisprudencia de la corte de apelaciones de concepción. Comentario a las sentencias 7800-2020, 9692-2020 y $11125-2020$.

una regla uniforme y común a todo tipo de actividad: "manténgase la prohibición de eventos públicos con más de 50 personas por un periodo de manera indefinida (sic) y eventos deportivos profesionales y aficionados, decretadas por el Ministerio de Salud, mediante Resolución Exenta № 215 de 30.03.2020, como las demás medidas sanitarias impuestas en dicho acto administrativo". A fin de cuentas, hacía aplicable en la región, las mismas normas establecidas a nivel nacional: prohibición de reuniones de más de 50 personas.

Por tanto, si bien lo que correspondía era declarar inadmisible el recurso de protección intentado, puesto que carecía de objeto (la resolución recurrida ya había sido derogada), la Corte de Apelaciones de Concepción no sólo lo admitió a trámite, sino que concedió, asimismo, la Orden de No Innovar invocada por el recurrente. Como ya señalaremos en el punto III.3, esto provocó una confusión en el resto de las autoridades encargadas de fiscalizar el cumplimiento de las medidas sanitarias, puesto que no había certeza sobre cuál era la resolución entonces vigente: ¿volvía a regir la Resolución №1094, que prohibía las actividades religiosas, o bien, dado que se trataba de una resolución posterior, debía primar la N¹529? Nos centraremos más adelante en este punto.

Durante la tramitación del proceso, la llustrísima Corte de Apelaciones de Concepción recibió informes en derecho redactados tanto por instituciones sanitarias, como por organizaciones protectoras de los derechos humanos. Con ellos a la vista, y luego de oídos los alegatos de las partes y de algunos terceros intervinientes en el juicio, el día 22 de julio, la Corte dictó sentencia rechazando el recurso de protección, y dejando sin efecto la orden de no innovar previamente concedida.

En lo pertinente, la Corte resolvió rechazar el recurso de protección al indicar: "SEXTO: Que, así las cosas, y teniendo en especial consideración que el recurrente de autos procura, a través de esta acción constitucional, que "se deje sin efecto la Resolución exenta №1509 del 05 de mayo de 2020", que levanta la "medida sanitaria de prohibición de celebrar actividades religiosas", no cabe sino concluir que, la acción de protección de autos carece de 
Macarena Bustamante y Roberto Astaburuaga: La protección de la libertad de culto en tiempos de pandemia: la jurisprudencia de la corte de apelaciones de concepción. Comentario a las sentencias 7800-2020, 9692-2020 y $11125-2020$.

objeto y ha perdido oportunidad, toda vez que se ha satisfecho la pretensión del recurrente, incluso, antes de deducirse esta acción cautelar, no existiendo, por tanto, medida protectora alguna que esta Corte pueda adoptar" 10 .

\section{SENTENCIA DE LA CORTE DE APELACIONES DE CONCEPCIÓN, DEL 23 DE JULIO DE 2020, ROL N 11125-2020.}

En tercer lugar, el 6 de junio de 2020, un conjunto de pastores de la Región del Bío Bio interpuso un recurso de amparo en contra de la Seremi de Salud de la Región del Bío Bio, de la Intendencia de la Región del Bío Bio y en contra quienes resultaren responsables.

Tal acción tuvo por origen la detención arbitraria y arresto ilegal que sufrieron dos pastores al celebrar culto en sus respectivas iglesias, aunque estuvieran cumpliendo todas las medidas sanitarias vigentes. El primero de ellos fue detenido el día 16 de mayo de 2020, por infracción a las normas sanitarias, habiendo incurrido además en el delito contemplado en el artículo 318 del Código Penal. Sin embargo, se declaró ilegal la detención por no existir norma alguna que prohibiera el funcionamiento de las iglesias.

En cuanto al segundo pastor, éste se encontraba celebrando un culto cuando inspectores municipales se presentaron en el templo y le indicaron que no existía autorización para ello. A continuación, Ilamaron a Carabineros, efectuando una denuncia. El pastor fue detenido, pero no alcanzó a ser formalizado, al ser dada por la Fiscalía, una orden para dejarlo en libertad.

El último hecho que motivó la presentación del recurso, fueron los dichos de funcionarios de la Seremi de Salud el día 27 de mayo al segundo pastor, haciéndole saber

\footnotetext{
10 Ilustrísima Corte de Apelaciones de Concepción, Rol N. 9692-2020, sentencia definitiva 22 de julio de 2020, considerando $6^{\circ}$.
} 
Macarena Bustamante y Roberto Astaburuaga: La protección de la libertad de culto en tiempos de pandemia: la jurisprudencia de la corte de apelaciones de concepción. Comentario a las sentencias 7800-2020, 9692-2020 y $11125-2020$.

que no se podía realizar ningún tipo de actividad religiosa, aunque fuera de una persona, en virtud de la Resolución Exenta N 341 del Ministerio de Salud ${ }^{11}$.

Ante esto, los pastores de distintas iglesias de la Región del Bío Bio, manifestaron su inquietud y temor por ver amenazada su libertad personal en caso de decidir celebrar culto en sus templos, ya que el actuar de funcionarios municipales y de Carabineros obedecía a una supuesta normativa sanitaria que prohibía la celebración de actividades religiosas. Esta confusión respecto de cuál era la normativa vigente, pudo haber sido consecuencia, como anunciamos en el punto III.2, de la concesión de la orden de no innovar por parte de la Corte de Apelaciones de Concepción, en la causa Rol N9692-2020.

Es por lo anterior, que el recurso de marras tenía por objeto que se aclarara cuál era la normativa sanitaria vigente para que la autoridad pública no volviese a vulnerar la libertad personal de aquellos ministros de culto que ejercieran legítimamente su derecho fundamental a la libertad religiosa y de culto. Si bien la Corte admitió a tramitación el recurso, consideró que los hechos denunciados debían ser "conocidos a través de la ritualidad de un recurso de protección de modo que no se emitirá pronunciamiento en cuanto a la acción constitucional de amparo, ordenándose ingresar en el libro de recursos de protección para proseguir con su tramitación"12. Una vez que se tuvo por interpuesto el recurso de protección, la lltma. Corte ordenó a diferentes instituciones evacuar oficios sobre la materia y, habiendo oído alegatos de las partes, el 23 de julio acogió el recurso.

En lo pertinente, la Corte declaró:

“15\%) Que el artículo 19 N$^{\circ} 6$ de nuestra Carta Fundamental garantiza a todas las personas la "libertad de conciencia, la manifestación de todas las creencias y el ejercicio libre

\footnotetext{
${ }^{11}$ Normas relevantes de dicha resolución en el caso comentado son el Nㅜ 24 que ordenaba: "Dispóngase el uso obligatorio de mascarillas para todas las personas en espacios cerrados, siempre que se encuentren 10 o más personas en un mismo espacio, independiente de la naturaleza del espacio y de la actividad que ahí se realice", y el N²8 que establecía: "Prohíbase toda concentración de más de 50 personas en un lugar determinado, independiente de su naturaleza o de si se efectúa en espacios abiertos o cerrados".

12 Ilustrísima Corte de Apelaciones de Concepción, Rol №154-2020, resolución judicial, 6 de junio de 2020.
} 
Macarena Bustamante y Roberto Astaburuaga: La protección de la libertad de culto en tiempos de pandemia: la jurisprudencia de la corte de apelaciones de concepción. Comentario a las sentencias 7800-2020, 9692-2020 y $11125-2020$.

de todos los cultos que no se opongan a la moral, a las buenas costumbres o al orden público" y, al mismo tiempo, confiere a las "confesiones religiosas" la facultad de "erigir y conservar templos y sus dependencias bajo las condiciones de seguridad e higiene fijadas por las leyes y las ordenanzas". Lo anterior importa tanto la obligación del Estado de no perturbar, amenazar o restringir el ejercicio de la libertad religiosa, como también la obligación de aceptar los credos que cumplan los requisitos antes indicados, a fin de asegurar su libre ejercicio a todas las personas, sin distinción.

$\left.16^{\circ}\right)$ Que, por otra parte, la libertad de cultos comprende, según lo precisan la letra b) del artículo $6^{\circ}$ y la letra a) del artículo 7 de la Ley № 19.638 que establece normas sobre constitución de iglesias y organizaciones religiosas, la facultad de las personas para practicar en público o en privado, individual o colectivamente, actos de oración o de culto, conmemorar las festividades, celebrar sus ritos, observar su día de descanso semanal, así como también la facultad de reunirse o manifestarse públicamente con fines religiosos y asociarse para desarrollar comunitariamente sus actividades religiosas, de conformidad con el ordenamiento jurídico general y con esta ley. Ejercer libremente su propio ministerio, practicar el culto, celebrar reuniones de carácter religioso y fundar y mantener lugares para esos fines.

$17^{\circ}$ ) Que, en consecuencia, las normas antes citadas llevan a concluir que la SEREMI de Salud del Biobío, al dictar la resolución N 1.094 de 23 de marzo pasado, "prohibiendo" las actividades religiosas, se apartó del mandato constitucional y de la ley antes señalada, toda vez que el artículo 43 inciso tercero, de la Constitución Política de la República, al referirse al estado de excepción constitucional de catástrofe, (D.S. 104 del Ministerio del Interior u Seguridad Pública antes indicado), concede solo al Presidente de la República la facultad de "restringir" las libertades de locomoción y de reunión; más no la de suprimir o suspender tales derechos. 
Macarena Bustamante y Roberto Astaburuaga: La protección de la libertad de culto en tiempos de pandemia: la jurisprudencia de la corte de apelaciones de concepción. Comentario a las sentencias 7800-2020, 9692-2020 y $11125-2020$.

18) Que, en efecto, la Ley N¹8.415 Orgánica Constitucional de los Estados de Excepción, dispone en su artículo $1^{\circ}$ que, "el ejercicio de los derechos y garantías que la Constitución Política asegura a todas las personas, sólo puede ser afectado en las situaciones en que ésta lo autoriza y siempre que se encuentren vigentes los estados de excepción que ella establece." Y en su artículo 12 establece: "Entiéndese que se suspende una garantía constitucional cuando temporalmente se impide del todo su ejercicio durante la vigencia de un estado de excepción constitucional". "Asimismo, entiéndese que se restringe una garantía constitucional cuando, durante la vigencia de un estado de excepción, se limita su ejercicio en el fondo o en la forma".

$19^{\circ}$ ) Que, en consecuencia, solo el Presidente de la República tiene la facultad de restringir el derecho de reunión en el estado de catástrofe por calamidad pública en que se encuentra el país desde el 18 de marzo pasado, más nunca "prohibir" el derecho a reunirse de las personas con ocasión de la celebración de un culto religioso. De allí entonces, que el Ministerio de Salud al dictar la Resolución Exenta 341 sólo "restringe" el derecho a reunión a que esta no supere la cantidad de 50 personas, cualquiera sea el motivo de ella.

$20^{\circ}$ ) Que, en consecuencia, la detención de don Néstor Rivera Ortega y de don Leonel Espinoza Pino, en las ocasiones relatadas en los motivos anteriores, obedeció al cumplimiento de un acto administrativo ilegal y arbitrario, toda vez que la autoridad que lo expidió, obró fuera del ámbito de sus facultades legales, infringiendo el artículo $7^{\circ}$ de la Constitución Política de la República, y vulneró al mismo tiempo, la garantía que el mismo texto legal reconoce a las personas, en el artículo $19 \mathrm{~N}^{\circ} 13$, esto es, el derecho a reunirse pacíficamente sin permiso previo y sin armas, respecto de los señores Rivera Ortega y Espinoza Pino, el que se encuentra protegido mediante la acción de protección en el artículo 20 del mismo texto legal; quienes además, fueron privados de libertad, en las oportunidades establecidas en el considerando $12^{\circ}$ de esta sentencia". 


\section{EVOLUCIÓN DE LA JURISPRUDENCIA DE LA CORTE DE APELACIONES DE CONCEPCIÓN}

Antes de iniciar el análisis, es necesario hacer una breve mención acerca del derecho a la libertad religiosa. En estricto rigor, nuestra Constitución no consagra expresamente tal libertad, como señala el Profesor Jorge Precht ${ }^{13}$, sino que sólo se garantiza "la libertad de conciencia, la manifestación de todas las creencias y el libre ejercicio de todos los cultos que no lo opongan a la moral, a las buenas costumbres y al orden público". Sin embargo, Chile ha incorporado tratados internacionales de derechos humanos que consagran tal derecho, además de reconocer en la Ley Nº 19.638 la libertad religiosa y de culto (artículo $1^{\circ}$ ).

Se ha entendido por la doctrina que el derecho fundamental es la libertad religiosa, y que posee una manifestación interna y otra externa. El plano interno consiste en uno perteneciente a la persona, como "un claustro íntimo de creencias y por tanto, un espacio de autodeterminación intelectual ante el fenómeno religioso vinculado a la propia personalidad y dignidad individual"14. Respecto a la segunda, ésta se conoce como libertad de culto, "la que permite el ejercicio de todas las actividades que constituyen manifestaciones o expresiones del fenómeno religioso, entre ellos la práctica de los actos correspondientes a las ceremonias representativas vinculadas a la respectiva creencia religiosa, el derecho a recibir asistencia religiosa, recibir e impartir enseñanza e información religiosa de toda índole de acuerdo con las propias convicciones"15, o simplemente a la

\footnotetext{
13 PRECHT PIZARRO, Jorge, La libertad religiosa, Revista de Derecho de la Pontificia Universidad Católica de Valparaíso, $N^{\circ} 21$, octubre de 2010, p. 109. Consultado el 21 de diciembre de 2020 (Disponible en: http://www.rdpucv.cl/index.php/rderecho/article/view/458/429)

${ }^{14}$ Sentencia del Tribunal Constitucional Español 177/1996, de 11 de noviembre.

${ }^{15}$ NOGUEIRA ALCALA, Humberto. La libertad de conciencia, la manifestación de creencias y la libertad de culto en el ordenamiento jurídico chileno. lus et Praxis, Talca, v. 12, n. 2, p. 13-41, 2006. Disponible en https://scielo.conicyt.cl/scielo.php?script=sci arttext\&pid=S0718-00122006000200002\&lng=es\&nrm=iso (Consultado el 18 dic. 2020. http://dx.doi.org/10.4067/\$0718-00122006000200002).
} 
Macarena Bustamante y Roberto Astaburuaga: La protección de la libertad de culto en tiempos de pandemia: la jurisprudencia de la corte de apelaciones de concepción. Comentario a las sentencias 7800-2020, 9692-2020 y $11125-2020$.

manifestación externa de las creencias religiosas ${ }^{16}$. Para efectos de este comentario, ambos términos -libertad religiosa y libertad de culto-, serán usados cómo sinónimos.

Aclarado lo anterior, a la luz de las sentencias referidas es posible apreciar que la Corte de Apelaciones de Concepción fue modificando su criterio en cuanto abrirse a conocer el fondo de los recursos de protección que tuviesen por objeto actos administrativos que afectaran ilegítimamente la libertad de culto. Así también, y al mismo tiempo, fue ampliando las razones o motivos para fundamentar sus resoluciones sobre la materia.

En efecto, en el primer caso, la Corte de Apelaciones de Concepción declaró inadmisible el recurso de protección intentado por los laicos de la Catedral de Los Ángeles, al estimar que éste versaba sobre "la adopción de estrategias propias de la determinación de políticas públicas para hacer frente a la afectación sanitaria", decisión que fue confirmada por la Corte Suprema, la cual estimó que, además, debía tenerse presente el inciso $2^{\circ}$ del artículo $19 \mathrm{~N}^{\circ} 6$ de la Constitución Política, según el cual las confesiones religiosas pueden erigir y conservar templos. De esta forma, no se llegó a conocer el fondo del asunto, dado que ambos Tribunales, por diferentes razones, estimaron que no era procedente el recurso de protección interpuesto, manteniendo la medida de cierre de la Catedral y otras iglesias católicas de la ciudad de Los Ángeles.

A partir de lo expuesto, consideramos que en la decisión de la Corte de Apelaciones existe una confusión relativa a cuál es la cosa pedida por los recurrentes. Así, a nuestro juicio, la impugnación de una medida ilegal que provoca el cierre de establecimientos religiosos no tiene por objeto revertir políticas públicas sanitarias para hacer frente a la afectación sanitaria provocada por el Covid-19, sino que se aplicasen a la región del Bio Bío las mismas medidas sanitarias establecidas a nivel nacional. En efecto, en ese momento, la prohibición

\footnotetext{
${ }^{16}$ PRIORA, Juan Carlos, Libertad de conciencia, libertad religiosa, libertad de culto y tolerancia en el contexto de los derechos humanos (perspectiva histórico-bíblica), Enfoques XIV, 1 y 2 (2002), p.39. Disponible en: file:///C:/Users/Judicial\%20CyJ/Downloads/Dialnet-LibertadDeConcienciaLibertadReligiosaLibertadDeCul7352838.pdf (Consultado el 17 de diciembre de 2020).
} 
Macarena Bustamante y Roberto Astaburuaga: La protección de la libertad de culto en tiempos de pandemia: la jurisprudencia de la corte de apelaciones de concepción. Comentario a las sentencias 7800-2020, 9692-2020 y $11125-2020$.

vigente en todo Chile refería únicamente a los eventos públicos de más de 20 personas y al cierre de ciertos establecimientos, como cines, teatros, pubs, discotecas y otros lugares análogos; sin incluir en ningún caso, respecto de esta prohibición de funcionamiento, a los templos religiosos. Sin embargo, a nivel regional, la Seremi de Salud del Bio Bío, sin motivo razonable, prohibía la celebración de actividades religiosas- lo que fue además interpretado de manera absoluta- permitiendo al mismo tiempo el funcionamiento de locales comerciales, sin distinción, con un máximo de 50 personas. La discriminación arbitraria e injustificada en el trato dado a las iglesias era patente. Más aún si consideramos que la libertad religiosa es uno de los derechos esenciales que emanan de la naturaleza humana, anteriores al Estado y que, además, no admiten suspensión alguna, ni aún en estados de excepción constitucional, según lo dispone la Convención Americana de Derechos Humanos.

Es por ello que el recurso de protección intentado tenía por objeto dirigirse contra una Resolución Exenta ilegal e inconstitucional, así como en contra de un acto de clausura ilegal y arbitrario. Sin embargo, el criterio usado por la Corte de Apelaciones de Concepción al declarar inadmisible el recurso de protección obliga a entender que cualquier acto de la Administración que afecte derechos garantizados constitucionalmente no podría ser impugnado por tal vía. Ello traería como consecuencia que los Tribunales no podrían cumplir con el mandato constitucional de velar para que los derechos fundamentales no sean injustamente afectados. Es la misma Constitución la que regula su protección en estos eventos, siendo su artículo 45 es claro al señalar que: "Los tribunales de justicia no podrán calificar los fundamentos ni las circunstancias de hecho invocadas por la autoridad para decretar los estados de excepción, sin perjuicio de lo dispuesto en el artículo 39. No obstante, respecto de las medidas particulares que afecten derechos constitucionales, siempre existirá la garantía de recurrir ante las autoridades judiciales a través de los recursos que corresponda $(\ldots)^{\prime \prime}$.

Por su parte, la Corte Suprema, al confirmar la resolución que declaró inadmisible el recurso de protección, se fundó en la norma del inciso $2^{\circ}$ del artículo $19 \mathrm{~N}^{\circ} 6$ de la 
Macarena Bustamante y Roberto Astaburuaga: La protección de la libertad de culto en tiempos de pandemia: la jurisprudencia de la corte de apelaciones de concepción. Comentario a las sentencias 7800-2020, 9692-2020 y $11125-2020$.

Constitución, relativo al derecho de las confesiones religiosas a "erigir y conservar templos", cuestión que no tenía ninguna relación con lo discutido por las partes. En efecto, lo pedido por los recurrentes era la revocación de una resolución ilegal y el acto de clausura fundado en ella, sin que existiese controversia alguna respecto a la construcción o mantención de los templos católicos afectados. Lo que se buscaba era la correcta aplicación de las políticas sanitarias por la Seremi de Salud, y no la impugnación de ellas, por lo que, en un voto disidente, el Ministro Muñoz correctamente consideró que debía declararse admisible el recurso y darle la tramitación correspondiente.

En el segundo caso, sin embargo, es posible observar una diferencia sustancial en el modo de resolver de la Corte. Tan sólo unos días más tarde de haber declarado inadmisible el recurso de protección intentado por los laicos de la ciudad de Los Ángeles, la Corte de Apelaciones de Concepción admitió a trámite una acción de la misma naturaleza, sólo que con un objeto contrario al primero.

Como ya nos referimos en el punto III.2., con fecha 5 de mayo se dictó la Resolución Exenta N 1509, y con fecha 7 de mayo se dictó la Resolución Exenta Nº 1529. Esta segunda acción de protección se dirigió en contra de la resolución №1509. Así, si el recurso de protección intentado en contra de la resolución 1094, tenía por objeto la eliminación de la prohibición de celebrar actividades religiosas, en el segundo lo pedido era la revocación de la resolución que había alzado dicha prohibición, por estimar dicha medida como contraria a la salud pública. Es decir, la Corte había rechazado el primer recurso de protección por considerar que la acción de protección no podía tener por objeto la revisión de política públicas privativas del Ejecutivo (cuando éstas suspendían el ejercicio legítimo de derechos fundamentales), pero consideró que, en este caso, ello sí era admisible, aun cuando la resolución recurrida alzara dichas restricciones.

No obstante esta contradicción, la Corte finalmente optó por rechazar el recurso, fundando su decisión básicamente en una razón de carácter procesal: la resolución recurrida 
Macarena Bustamante y Roberto Astaburuaga: La protección de la libertad de culto en tiempos de pandemia: la jurisprudencia de la corte de apelaciones de concepción. Comentario a las sentencias 7800-2020, 9692-2020 y $11125-2020$.

había sido revocada con anterioridad a la interposición de la acción cautelar y, por tanto, lo solicitado por el recurrente ya había sido otorgado, razón que obligaba a desestimar la acción de protección intentada por haber perdido oportunidad. Cabe señalar que, si bien la Corte realizó un razonamiento que consideramos correcto, prefirió no profundizar en razones de carácter sustantivo respecto a la especial protección de la cual es merecedora la libertad religiosa como derecho fundamental.

Finalmente, en el tercer caso, relativo a la acción que dedujeron un número de pastores evangélicos temerosos de verse privados de su libertad personal como consecuencia de la celebración del culto, la Corte no sólo admitió a tramitación el recurso de amparo, ordenando su tramitación según las reglas del recurso de protección, sino que también -y por esto constituye un fallo excepcional- señaló claramente los límites que pueden establecerse en el ejercicio de la libertad de culto durante un estado de excepción, distinguiendo claramente entre las facultades de restricción y prohibición del ejercicio de garantías constitucionales que tiene el Estado.

El primer aspecto a destacar en esta sentencia es la obligación del Estado de respetar el ejercicio de la libertad religiosa. Aquí, los jueces directamente señalaron que las obligaciones del Estado en la materia consisten en "no perturbar, amenazar o restringir el ejercicio de la libertad religiosa"17.

Sin embargo, el razonamiento de la Corte fue más allá, señalando que el Estado tiene por fin, respecto a la aceptación de los credos religiosos, "asegurar su libre ejercicio a todas las personas"18. En efecto, no basta solo con la abstención estatal en estas materias, sino que, debido al objeto protegido por este derecho, y que entronca directamente con la mayor realización espiritual de la persona humana, es necesario que el Estado disponga los medios necesarios para garantizar el ejercicio del derecho. Por tanto, si es que el deber del Estado

\footnotetext{
${ }^{17}$ Ilustrísima Corte de Apelaciones de Concepción, Rol Nº. 11125-2020, sentencia definitiva, 23 de julio de 2020, considerando $15^{\circ}$.

18 Ídem.
} 
Macarena Bustamante y Roberto Astaburuaga: La protección de la libertad de culto en tiempos de pandemia: la jurisprudencia de la corte de apelaciones de concepción. Comentario a las sentencias 7800-2020, 9692-2020 y $11125-2020$.

no sólo se reduce a abstenerse de interferir en el ejercicio de la libertad religiosa, sino que también consiste en permitir y promover la existencia de condiciones para dicho ejercicio, las limitaciones o restricciones deben ser suficientemente justificadas, aplicadas en igualdad de condiciones, proporcionales y de breve temporalidad.

Luego, la sentencia profundiza sobre una manifestación de la libertad religiosa. En efecto, la Ley $\mathrm{N}^{\circ} 19.638$ reconoce a las personas la facultad de practicar públicamente actos de oración y culto, así como también "la facultad de reunirse o manifestarse públicamente con fines religiosos y asociarse para desarrollar comunitariamente sus actividades religiosas, de conformidad con el ordenamiento jurídica general y con esta ley"19.

En tercer lugar, la sentencia establece claramente que la Resolución Exenta N 1094 era inconstitucional e ilegal ${ }^{20}$ al "prohibir" las actividades religiosas, cuando realmente el estado de excepción constitucional de catástrofe sólo concede "la facultad de "restringir" las libertades de locomoción y de reunión; más no la de suprimir o suspender tales derechos". Es esta distinción la que llevará a la Corte a denunciar claramente que la Autoridad Sanitaria no tiene la facultad de prohibir el derecho de las personas a reunirse con ocasión de la celebración de un culto religioso.

Por estos motivos la Corte de Apelaciones de Concepción resolvió que las detenciones de los pastores obedecieron al cumplimiento de un acto administrativo ilegal y arbitrario, ya que se apartaba de la forma en que la ley prescribe el ejercicio de libertad religiosa -artículo $7^{\circ}$ de la Constitución Política- y al mismo tiempo vulneraba el derecho a reunirse pacíficamente sin permiso previo y sin armas -artículo $19 \mathrm{~N}^{\circ} 13-$.

\footnotetext{
19 ídem., considerando $16^{\circ}$.

20 “(...) se apartó del mandato constitucional y de la ley (...)”. Iltma. Corte de Apelaciones de Concepción, Rol N 11125-2020, considerando $17^{\circ}$.
} 
Macarena Bustamante y Roberto Astaburuaga: La protección de la libertad de culto en tiempos de pandemia: la jurisprudencia de la corte de apelaciones de concepción. Comentario a las sentencias 7800-2020, 9692-2020 y $11125-2020$.

Sin embargo, a nuestro juicio el aspecto más importante de esta sentencia es la distinción realizada por la Corte entre restringir o limitar el ejercicio de un derecho fundamental, y prohibirlo, suspenderlo o suprimirlo.

Al efecto, la sentencia cita la Ley N¹8.415 Orgánica Constitucional de los Estados de Excepción, y en el artículo 12 señala el significado de estas dos formas de limitar el ejercicio de los derechos y garantías de la Constitución Política. Así, la restricción de una garantía constitucional ocurre "cuando, durante la vigencia de un estado de excepción, se limita su ejercicio en el fondo o en la forma"21. En cambio, la suspensión de una garantía constitucional se produce "cuando temporalmente se impide del todo su ejercicio durante la vigencia de un estado de excepción constitucional"22. Por tanto, la restricción corresponde a la limitación en el fondo o en la forma y la suspensión a impedir temporalmente todo su ejercicio.

Según se observa, este fallo realiza una distinción que tiene efectos prácticos esenciales: si es que se limita el número de asistentes a una actividad religiosa, sólo existe una restricción -regulación de un elemento formal-, por lo que puede seguir ejerciéndose la libertad de culto. Sin embargo, ordenar el cierre de un templo religioso y prohibir actividades de culto públicas, constituye una prohibición absoluta de su ejercicio, ya que no hay medio ni posibilidad alguna de que los creyentes puedan, al menos, orar en el lugar especialmente destinado al efecto. Tal prohibición no se encuentra dentro de las facultades previstas en el estado excepcional de catástrofe ni es una limitación que afecte el fondo o la forma, sino derechamente impide totalmente el ejercicio del derecho. La Corte advirtiendo esta diferencia, restableció el imperio del derecho de los creyentes afectados.

21 ídem., considerando $18^{\circ}$.

22 Ídem. 


\section{CONSIDERACIONES SUSTANTIVAS SOBRE LAS RESOLUCIONES QUE PROHÍBEN LA CELEBRACIÓN DE ACTIVIDADES RELIGIOSAS}

Todas las resoluciones dictadas por las Seremis de Salud se fundan en el Estado de Emergencia y en las facultades extraordinarias concedidas a órganos del Estado por el Decreto $\mathrm{N}^{\circ} 4$ del Ministerio de Salud, que decretó la Alerta Sanitaria en el país. Sin embargo, cuando dichas resoluciones establecían la prohibición de celebrar actividades religiosas, adolecían de un vicio de ilegalidad por dos motivos, que exponemos a continuación.

En primer lugar, tales actos contravienen expresamente normas consagradas en tratados internacionales sobre derechos humanos, ratificados por Chile y actualmente vigentes, infringiendo así el inciso $2^{\circ}$ del artículo $5^{\circ}$ y el artículo $7^{\circ}$ de nuestra Carta Fundamental, como lo son el Pacto Internacional de Derechos Civiles y Políticos, y la Convención Americana de los Derechos Humanos.

El primero de los tratados mencionados reconoce la libertad religiosa, y establece que: "1. Toda persona tiene derecho a la libertad de pensamiento, de conciencia y de religión; este derecho incluye la libertad de tener o de adoptar la religión o las creencias de su elección, así como la libertad de manifestar su religión o sus creencias, individual o colectivamente, tanto en público como en privado, mediante el culto, la celebración de los ritos, las prácticas y la enseñanza (...)”. Este artículo debe leerse junto al artículo $4^{\circ}$ del mismo Pacto, el cual indica "1. En situaciones excepcionales que pongan en peligro la vida de la nación y cuya existencia haya sido proclamada oficialmente, los Estados Partes en el presente Pacto podrán adoptar disposiciones que, en la medida estrictamente limitada a las exigencias de la situación, suspendan las obligaciones contraídas en virtud de este Pacto, siempre que tales disposiciones no sean incompatibles con las demás obligaciones que les impone el derecho internacional y no entrañen discriminación alguna fundada únicamente en motivos 
Macarena Bustamante y Roberto Astaburuaga: La protección de la libertad de culto en tiempos de pandemia: la jurisprudencia de la corte de apelaciones de concepción. Comentario a las sentencias 7800-2020, 9692-2020 y $11125-2020$.

de raza, color, sexo, idioma, religión u origen social. 2. La disposición precedente no autoriza suspensión alguna de los artículos 6, 7, 8 (párrafos 1 y 2), 11, 15, 16 y 18 (...)”.

El segundo tratado, la Convención Americana sobre Derechos Humanos, reconoce este derecho y también le da una especial protección. El artículo 12 señala: "Libertad de Conciencia y de Religión 1. Toda persona tiene derecho a la libertad de conciencia y de religión. Este derecho implica la libertad de conservar su religión o sus creencias, o de cambiar de religión o de creencias, así como la libertad de profesar y divulgar su religión o sus creencias, individual o colectivamente, tanto en público como en privado. 2. Nadie puede ser objeto de medidas restrictivas que puedan menoscabar la libertad de conservar su religión o sus creencias o de cambiar de religión o de creencias. 3. La libertad de manifestar la propia religión y las propias creencias está sujeta únicamente a las limitaciones prescritas por la ley y que sean necesarias para proteger la seguridad, el orden, la salud o la moral públicos o los derechos o libertades de los demás. 4. Los padres, y en su caso los tutores, tienen derecho a que sus hijos o pupilos reciban la educación religiosa y moral que esté de acuerdo con sus propias convicciones"; mientras que el artículo 27 lo resguarda al señalar: "“1. En caso de guerra, de peligro público o de otra emergencia que amenace la independencia o seguridad del Estado parte, éste podrá adoptar disposiciones que, en la medida y por el tiempo estrictamente limitados a las exigencias de la situación, suspendan las obligaciones contraídas en virtud de esta Convención, siempre que tales disposiciones no sean incompatibles con las demás obligaciones que les impone el derecho internacional y no entrañen discriminación alguna fundada en motivos de raza, color, sexo, idioma, religión u origen social. 2. La disposición precedente no autoriza la suspensión de los derechos determinados en los siguientes artículos: 3 (Derecho al Reconocimiento de la Personalidad Jurídica); 4 (Derecho a la Vida); 5 (Derecho a la Integridad Personal); 6 (Prohibición de la Esclavitud y Servidumbre); 9 (Principio de Legalidad y de Retroactividad); 12 (Libertad de Conciencia y de Religión); 17 (Protección a la Familia); 18 (Derecho al Nombre); 19 (Derechos del Niño); 20 (Derecho a la Nacionalidad), y 23 (Derechos Políticos), ni de las garantías judiciales indispensables para la protección de tales derechos." 
Macarena Bustamante y Roberto Astaburuaga: La protección de la libertad de culto en tiempos de pandemia: la jurisprudencia de la corte de apelaciones de concepción. Comentario a las sentencias 7800-2020, 9692-2020 y $11125-2020$.

Otros instrumentos internacionales también reconocen la especial naturaleza de este derecho y su debida protección, como el artículo 18 de la Declaración Universal de los Derechos del Hombre ${ }^{23}$ o el artículo $9^{\circ}$ del Convenio Europeo de los Derechos Humanos ${ }^{24}$.

La Corte Interamericana de Derechos Humanos se ha pronunciado directamente sobre la importancia, contenido y trascendencia de este derecho: "Según el artículo 12 de la Convención, el derecho a la libertad de conciencia y de religión permite que las personas conserven, cambien, profesen y divulguen su religión o sus creencias. Este derecho -la libertad de conciencia y religión- es uno de los cimientos de la sociedad democrática. En su dimensión religiosa, constituye un elemento trascendental en la protección de las convicciones de los creyentes y en su forma de vida"25.

De forma similar el Comité de Derechos Humanos de Naciones Unidas indica: El derecho a la libertad de pensamiento, de conciencia y de religión (que incluye la libertad de tener creencias) en el párrafo 1 del artículo 18 es profundo y de largo alcance; abarca la libertad de pensamiento sobre todas las cuestiones, las convicciones personales y el compromiso con la religión o las creencias, ya se manifiesten a título individual o en comunidad con otras personas" ${ }^{26}$. Es decir, como libertad civil y garantía de la expresión de la fe de las personas, es que los organismos internacionales no han dudado en resaltar su valor y rodearla de garantías que permitan su ejercicio, individual o comunitario, aun en situaciones excepcionales.

\footnotetext{
23 "Todo el mundo tiene derecho a la libertad de pensamiento, conciencia y religión; este derecho incluye la libertad para cambiar de religión o creencia y libertad para manifestar, ya sea solo o unido a otros y en público o privado, su religión o creencia tanto en la enseñanza como en la práctica, el culto o la observancia"

${ }^{24}$ 1. Toda persona tiene derecho a la libertad de pensamiento, de conciencia y de religión; este derecho implica la libertad de cambiar de religión o de convicciones, así como la libertad de manifestar su religión o sus convicciones individual o colectivamente, en público o en privado, por medio del culto, la enseñanza, las prácticas y la observancia de los ritos

${ }^{25}$ Sentencia de la Corte Interamericana de Derechos Humanos, Olmedo Bustos y otros versus Chile. Fondo, reparaciones y costas. 5 de febrero de 2001 (caso sobre la película "La última tentación de Cristo", párrafo 79). ${ }^{26}$ Comité de Derechos Humanos. Observación General N²2: Derecho a la libertad de pensamiento, de conciencia y de religión (art. 18), 1993, CCPR/C/21/Rev.1/Add.4, párr. 1, 2
} 
Macarena Bustamante y Roberto Astaburuaga: La protección de la libertad de culto en tiempos de pandemia: la jurisprudencia de la corte de apelaciones de concepción. Comentario a las sentencias 7800-2020, 9692-2020 y $11125-2020$.

Del mismo modo, distintos Tribunales internacionales se han pronunciado sobre las restricciones al culto religioso con ocasión de la pandemia. Así, el Tribunal Constitucional Alemán, fue llamado a analizar la prohibición general de reuniones en iglesias, mezquitas y otros templos, que no permitía ningún tipo de excepciones. En su orden del 2 de mayo de 2020, el tribunal resolvió provisionalmente que dicha prohibición del Lander de Baja Sajonia era inconstitucional, por vulnerar gravemente el derecho a la libertad religiosa ${ }^{27}$. Por su parte, el Consejo de Estado Francés, ordenó al Primer Ministro modificar en un plazo de 8 días, los actos administrativos que dispusieron una prohibición general y absoluta de actividades religiosas en lugares de culto, debiendo reemplazarlas por medidas proporcionadas al combate de la pandemia. En la decisión judicial se reconoce el carácter fundamental de la libertad religiosa, la que incluye como componente esencial el poder participar en ceremonias colectivas, y en particular, en lugares de culto ${ }^{28}$. También la Corte Suprema de Estados Unidos, en un fallo emblemático de fecha 25 de noviembre de 2020, en relación a ciertas medidas referentes a los cultos religiosos, impuestas por el Gobernador del Estado de Nueva York, dispuso lo siguiente:

"There can be no question that the challenged restrictions, if enforced, will cause irreparable harm. The loss of First Amendment freedoms, for even minimal periods of time, unquestionably constitutes irreparable injury". Elrod v. Burns, 427 U.S. 347, 373 (1976) (plurality opinion). If only 10 people are admitted to each service, the great majority of those who wish to attend Mass on Sunday or services in a synagogue on Shabbat will be barred. And while those who are shut out may in some instances be able to watch services on television, such remote viewing is not the same as personal attendance. Catholics who watch

\footnotetext{
27 Ver, Bundesverfassungsgericht, Tribunal Federal Constitucional de Alemania, Segunda Sala, Primer Senado, decisión de 29 de abril de 2020, disponible en: https://www.bundesverfassungsgericht.de/SharedDocs/Entscheidungen/DE/2020/04/qk20200429_1bvq0044 20.html;jsessionid=6BECFA96894F86CABDDBDC64451F7AE1.2_cid392

28 Ver, Conseil d'État, Consejo de Estado Francés, decisión del 18 de mayo de 2020, disponible en: https://www.conseil-etat.fr/Media/actualites/documents/2020/05-mai/440366-et-suivants-m.-w-etautres.anon_compl.pdf
} 
Macarena Bustamante y Roberto Astaburuaga: La protección de la libertad de culto en tiempos de pandemia: la jurisprudencia de la corte de apelaciones de concepción. Comentario a las sentencias 7800-2020, 9692-2020 y $11125-2020$.

a Mass at home cannot receive communion, and there are important religious traditions in the Orthodox Jewish faith that require personal attendance"29.

El segundo motivo por el cual las referidas resoluciones son ilegales consiste en que tales actos perturban el legítimo ejercicio de la libertad religiosa, que se encuentra consagrado en el numeral $6^{\circ}$ del artículo 19 de nuestra Constitución Política.

Conforme a esta norma ${ }^{30}$ se ha entendido que la libertad religiosa tiene una dimensión exterior, como lo es la libertad de culto, con la posibilidad de practicar el culto respectivo ya sea de forma privada o pública ${ }^{31}$. La práctica pública del culto generalmente se realiza al interior de recintos destinados especialmente para estos efectos (iglesias, templos, sinagogas, mezquitas, etc.).

Con la prohibición de actividades religiosas por parte de las autoridades sanitarias, se infringe el principio de juridicidad consagrado en el artículo $7^{\circ}$ de nuestra Constitución, porque un órgano del Estado -las Seremis de Salud- no están actuando en la "forma prescrita por la ley", ya que dentro de las facultades entregadas excepcionalmente solo se contempla la de restringir determinados derechos, mas no prohibirlos.

${ }^{29}$ SUPREME COURT OF THE UNITED STATES (2020): "ROMAN CATHOLIC DIOCESE OF BROOKLYN, NEW YORK V. ANDREW M. CUOMO, GOVERNOR OF NEW YORK", November 25, 2020, 592 U.S., p. 5.

30 "La libertad de conciencia, la manifestación de todas las creencias y el ejercicio libre de todos los cultos que no se opongan a la moral, a las buenas costumbres y al orden público. Las confesiones religiosas podrán erigir y conservar templos y sus dependencias bajo las condiciones de seguridad e higiene fijadas por las leyes y ordenanzas. Las iglesias, las confesiones e instituciones religiosas de cualquier culto tendrán los derechos que otorgan y reconocen, con respecto a los bienes, las leyes actualmente en vigor. Los templos y sus dependencias, destinadas al culto, estarán exentos de toda clase de contribuciones".

${ }^{31}$ El Comité de Derechos Humanos también se ha referido estas dos dimensiones y respecto a la segunda ha indicado: "La libertad de manifestar la propia religión o las propias creencias puede ejercerse "individual o colectivamente, tanto en público como en privado". La libertad de manifestar la religión o las creencias mediante el culto, la celebración de los ritos, las prácticas y la enseñanza abarca una amplia gama de actividades. El concepto de culto se extiende a los actos rituales y ceremoniales con los que se manifiestan directamente las creencias, así como a las diversas prácticas que son parte integrante de tales actos, comprendidos la construcción de lugares de culto, el empleo de fórmulas y objetos rituales, la exhibición de símbolos y la observancia de las fiestas religiosas y los días de asueto (...)". Comité de Derechos Humanos. Observación General N²2: Derecho a la libertad de pensamiento, de conciencia y de religión (artículo 18), 1993, CCPR/C/21/Rev.1/Add.4, párr. 4. 
Macarena Bustamante y Roberto Astaburuaga: La protección de la libertad de culto en tiempos de pandemia: la jurisprudencia de la corte de apelaciones de concepción. Comentario a las sentencias 7800-2020, 9692-2020 y $11125-2020$.

En este sentido, cualquier acto fiscalizador fundado en resoluciones administrativas que prohíben actividades religiosas haciendo imposible su ejercicio, ya sea por restricciones de forma o fondo, confirman dicha ilegalidad e inconstitucionalidad, en virtud de lo dispuesto en el artículo 19 N²6 de la Constitución Política: "La seguridad de que los preceptos legales que por mandato de la Constitución regulen o complementen las garantías que ésta establece o que las limiten en los casos en que ella lo autoriza, no podrán afectar los derechos en su esencia, ni imponer condiciones, tributos o requisitos que impidan su libre ejercicio".

De este modo, actos como la clausura de iglesias, la solicitud de mantención de la prohibición de celebrar actividades religiosas o la detención de pastores que celebran culto conforme a las normativas pertinentes, implican en los hechos la suspensión del derecho de las personas a practicar públicamente su culto.

Finalmente es posible analizar estas resoluciones desde la perspectiva de su arbitrariedad:

Sostenemos que son arbitrarias por vulnerar el artículo $19 \mathrm{~N}^{\circ} 2$ de la Constitución Política, que establece: "La Constitución asegura a todas las personas: $2^{\circ}$. La igualdad ante la ley. En Chile no hay persona ni grupos privilegiados. En Chile no hay esclavos y el que pise su territorio queda libre. Hombres y mujeres son iguales ante la ley. Ni la ley ni autoridad alguna podrán establecer diferencias arbitrarias".

La igualdad ante la ley consiste en que las normas jurídicas deben ser iguales para todos los que se encuentran en las mismas circunstancias y, consecuencialmente, diversas para aquellos que se encuentran en situaciones diferentes ${ }^{32}$. Por tanto, en virtud del artículo $19 N^{\circ} 2$ de la Constitución Política de la República, la autoridad debe tratar de modo

\footnotetext{
32 Vid. Sentencias del Tribunal Constitucional, Rol № 53-88 y Rol № 219-95.
} 
Macarena Bustamante y Roberto Astaburuaga: La protección de la libertad de culto en tiempos de pandemia: la jurisprudencia de la corte de apelaciones de concepción. Comentario a las sentencias 7800-2020, 9692-2020 y $11125-2020$.

igualitario a quienes se encuentren en condiciones o circunstancias similares, siguiendo el aforismo que sostiene que "hay que tratar igual lo igual y desigual a lo desigual"33. Así, lo que se sanciona es "toda diferenciación o distinción, realizada por el legislador o cualquiera autoridad pública, que aparezca como contraria a la ética elemental o a un proceso normal de análisis intelectual, en otros términos, que no tenga justificación racional o razonable"34. De esta manera, la discriminación viene a ser para algunos, sinónimo de diferencia arbitraria, esto es, "la desigualdad de tratamiento de las personas carente de justificación objetiva y razonable", como asimismo "el tratamiento igual de personas que se encuentran en situaciones en que hay diferencias jurídicas relevantes, que obligarían a un tratamiento diferenciado" 35 .

Así, si las resoluciones sanitarias disponen, por un lado, la prohibición de celebración de actividades religiosas y que constituyan aglomeración de personas y, al mismo tiempo, establecen una restricción al ingreso de locales comerciales de un número que no supere las 50 personas, la arbitrariedad se manifiesta en el hecho de que las medidas sanitarias que exige la autoridad a las instalaciones comerciales pueden ser puestas en práctica sin mayor problema por los establecimientos religiosos. No hay, por tanto, razón alguna para excluirlas, sino al contrario, deberían aplicárseles las mismas- o menores, incluso- restricciones o limitaciones, como establecer el máximo de personas que pueden ingresar en los establecimientos, de acuerdo al tamaño de éstos, el uso obligatorio de mascarillas, el distanciamiento social, etc.

Por otra parte, pensamos que estas resoluciones constituyen medidas desproporcionadas, atendido el fin que con ellas se busca alcanzar. Evitar el contagio y propagación del Covid-19 puede alcanzarse con medidas menos lesivas para los derechos de

\footnotetext{
${ }^{33}$ ALEXY, Robert, Teoría de los derechos fundamentales, Centro de Estudios Constitucionales, Madrid, 1997, p. 385.

${ }^{34}$ EVANS DE LA CUADRA, Enrique, Los derechos constitucionales, Tomo II, Editorial Jurídica de Chile, Santiago, 2004, p. 125.

35 NOGUEIRA ALCALÁ, Humberto, Derechos fundamentales y garantías constitucionales, Tomo II, Editorial Librotecnia, Santiago, 2010, p. 272.
} 
Macarena Bustamante y Roberto Astaburuaga: La protección de la libertad de culto en tiempos de pandemia: la jurisprudencia de la corte de apelaciones de concepción. Comentario a las sentencias 7800-2020, 9692-2020 y $11125-2020$.

los fieles católicos, evangélicos o cualquier otro, a través de la limitación del número de asistentes, el establecimiento de horarios de asistencia, la distancia que debe mantenerse entre los fieles, la limpieza constante del lugar, el uso de mascarillas y controles de temperatura, etc. Muchas de estas medidas han sido aplicadas por las distintas confesiones religiosas, para que las personas puedan asistir presencialmente a los establecimientos religiosos a través de Protocolos y Planes de asistencia según etapas de restricción.

El Tribunal Constitucional ha señalado que no basta con que la justificación de las diferencias sea razonable, sino que además debe ser objetiva y proporcional ${ }^{36}$. Para determinar si es desproporcionada debe revisarse la finalidad perseguida para intervenir el derecho fundamental, la cual debe ser adecuada, necesaria y tolerable para el destinatario de la misma.

De este modo, "resulta sustancial efectuar un examen de racionalidad de la distinción; a lo que debe agregarse la sujeción a la proporcionalidad, teniendo en cuenta las situaciones fácticas, la finalidad de la ley y los derechos afectados 37", "que debe estar en condiciones de tolerar tal afectación" ${ }^{\prime 3}$. Por tanto, el nuevo estándar de proporcionalidad analiza la relación entre fines y medios y consiste "en una revisión de la decisión adoptada por la Administración a la luz de los fines para los cuales se le ha otorgado la potestad en cuyo ejercicio ha adoptado una decisión" ${ }^{\prime 39}$. El principio de proporcionalidad, en consecuencia, es el que busca determinar si una actuación estatal y su intensidad, son jurídicamente las más adecuadas para conseguir un fin determinado, permitiendo evaluar si el acto es arbitrario y razonable ${ }^{40}$. La exigencia del logro del fin no se cumple si es que el

\footnotetext{
${ }^{36}$ Vid. AA.VV., El principio de proporcionalidad en el Estado Constitucional (coord. Miguel Carbonell), Ministerio de Justicia y Derechos Humanos de Colombia, Colombia, 2007, passim.

37 Sentencia del Tribunal Constitucional, Rol 1307-2009, aludiendo a la jurisprudencia sustentada en Roles $\mathrm{N}^{\circ}$ 755-2007, 790-2007, 1138-2008 y 1140-2008.

${ }^{38}$ Sentencias del Tribunal Constitucional, Roles №s. 1448-2009 y 1584-2009.

39 DE LA FUENTE CASTRO, Osvaldo. Control judicial de la resolución de calificación ambiental, Santiago, 2012, p. 120.

${ }^{40}$ ARNOLD, Reiner, MARTÍNEZ ESTAY, José Ignacio et al, "El principio de proporcionalidad en la jurisprudencia constitucional", Estudios constitucionales, vol.10, №1, Santiago, 2012, pp. 65-116. Disponible en
} 
Macarena Bustamante y Roberto Astaburuaga: La protección de la libertad de culto en tiempos de pandemia: la jurisprudencia de la corte de apelaciones de concepción. Comentario a las sentencias 7800-2020, 9692-2020 y $11125-2020$.

medio dispuesto no conduce claramente a su realización; esto implica que el acto administrativo no es integralmente proporcionado al fin que lo motiva y justifica y, por ello, es desproporcionado ${ }^{41}$ y carece de razonabilidad ${ }^{42}$.

Ahora bien, la proporcionalidad tiene dos dimensiones. La primera se refiere a la interdicción de las actuaciones o intervenciones excesivas de los poderes del Estado, debiendo éste contenerse dentro de sus límites, es decir, es un principio de protección de los derechos fundamentales, que permite regular la intervención estatal cuando afecta los derechos y libertades de las personas. En efecto, el principio general es la libertad del individuo y el goce y ejercicio legítimo de sus derechos y garantías, y la restricción o suspensión de ellos, la excepción.

Conforme a estas premisas, la Autoridad Sanitaria debe medir la intensidad e impacto de sus resoluciones en el individuo, ponderando el interés público con el interés individual. La intervención proporcional se expresa en diferentes grados según diferentes finalidades: mientras mayor sea la intervención en los derechos y libertades del individuo, mayor debe ser la justificación; y si es que la finalidad de la intervención estatal puede ser cumplida con una menor intensidad, tal alternativa debe siempre preferirse, de modo que la intervención estatal no debe ir más allá de la intensidad mínima necesaria para un cumplimiento eficaz del fin perseguido. Si los objetivos no son muy graves, los instrumentos de intervención deben ser de menor intensidad, y si es que el fin perseguido puede obtenerse con un menor grado de intervención, el Estado debe aplicar dicha restricción y no una mayor.

Así también, la racionalidad y proporcionalidad de las medidas sanitarias que restrinjan la libertad de culto deben ser siempre idóneas, necesarias y estrictamente proporcionales.

https://scielo.conicyt.cl/scielo.php?script=sci arttext\&pid=S0718-52002012000100003 (Consultado el 7 de octubre de 2020).

${ }^{41}$ Revista de Derecho y Jurisprudencia, 1983, T.80, № 2,2.5, pp. 40-45.

${ }^{42}$ Ibid, pp. 57- 65, y Revista de Derecho y Jurisprudencia., 1985, T. 82, № 2, 2.5, pp. 151-157. 
Macarena Bustamante y Roberto Astaburuaga: La protección de la libertad de culto en tiempos de pandemia: la jurisprudencia de la corte de apelaciones de concepción. Comentario a las sentencias 7800-2020, 9692-2020 y $11125-2020$.

Serán idóneas según la aptitud que tiene la decisión de la Administración para alcanzar el fin propuesto, de acuerdo a los conocimientos especializados. Este principio exige comprobar si la medida limitadora es, por sí misma, un medio apto para conseguir el fin público que la justifica.

Serán necesarias si, según se ha dicho, si el medio propuesto por la Administración es el menos incisivo sobre los intereses privados.

Y serán estrictamente proporcionales ${ }^{43}$ si la consecución del fin público pretendido por la Administración justifica o compensa el sacrificio del interés privado afectado por la medida ${ }^{44}$.

Por lo antedicho, prohibir la realización de actividades religiosas y/o clausurar templos religiosos como medidas de resguardo sanitario es un acto de suyo desproporcionado toda vez que se trata de medidas que no son idóneas ni razonables para alcanzar el fin propuesto, de acuerdo con los parámetros señalados.

Sin embargo, dos días después de la sentencia del 23 de julio de 2020 (Rol № 111252020), se dictó la Resolución Exenta N591 del Ministerio de Salud. Lo que jurídicamente Ilama la atención en relación al tema que venimos desarrollando es su artículo 44 bis, el cual establece las siguientes restricciones respecto de las actividades religiosas:

"44 bis. Se autoriza la realización de oficios, ritos, seminarios y ceremonias en las localidades que se encuentren en Paso 2, 3, 4 o 5, sujeto a las siguientes reglas:

a. Los oficios, ritos, seminarios o ceremonias no podrán exceder las dos horas de duración.

\footnotetext{
${ }^{43}$ SARMIENTO, Daniel, El principio de proporcionalidad en el Derecho Administrativo. Un análisis jurídico desde el Derecho Español, U. Externado de Colombia, Colombia, 2007, pp. 191 y ss.

44 CARLON RUIZ, Matilde, "El principio de proporcionalidad", en Los principios jurídicos del derecho administrativo (dir. Juan Alfonso Santamaría Pastor), 2010, 203-230 pp., pp. 207 y 208.
} 
Macarena Bustamante y Roberto Astaburuaga: La protección de la libertad de culto en tiempos de pandemia: la jurisprudencia de la corte de apelaciones de concepción. Comentario a las sentencias 7800-2020, 9692-2020 y $11125-2020$.

b. El aforo máximo de los espacios donde se efectúe el oficio, rito, seminarios o ceremonia, ya sean cerrados o abiertos, no podrá exceder de una persona por cada 4 metros cuadrados útiles.

c. Deberá darse estricto cumplimiento a las demás medidas sanitarias, según el paso en que se encuentre la localidad donde se emplaza el espacio en que se celebra el oficio, rito, seminario o ceremonia. En ningún caso podrá celebrarse un oficio, rito, seminario o ceremonia en localidades que se encuentren en cuarentena, o en Paso 2 durante los fines de semana y feriados. Sin perjuicio de lo anterior, los funerales se regirán por sus normas especiales.

d. Los asistentes deberán permanecer en una ubicación fija la mayoría del tiempo de duración de la actividad.

e. No se permite el consumo de alimentos ni bebidas.

f. Sin perjuicio de lo dispuesto en el literal b, los aforos máximos de los lugares donde se realicen los oficios, ritos, seminarios y ceremonias, según el Paso que se trate, en conformidad al Capítulo II de la presente resolución, serán los siguientes:

i. Paso 2 - Transición: 10 personas en un lugar cerrado y 20 personas en un lugar abierto, exceptuándose los fines de semana y festivos, en los que no está permitido la realización de oficios, ritos, seminarios o ceremonias.

ii. Paso 3 - Preparación: 50 personas en un lugar cerrado y 100 personas en un lugar abierto.

iii. Paso 4 - Apertura Inicial: 100 personas en un lugar cerrado y 200 personas en un lugar abierto.

iv. Paso 5 - Apertura Avanzada: 200 personas en un lugar cerrado y 400 personas en un lugar abierto" ${ }^{\prime 4}$.

Estas nuevas medidas sanitarias incluyen restricciones a las actividades religiosas, que impiden totalmente que en las comunas en Fase 1 y los fines de semana y festivos de las

\footnotetext{
45 Resolución Exenta $N^{\circ} 591$ del Ministerio de Salud, publicado el 25 de julio de 2020. Disponible en:
} https://www.bcn.cl/leychile/navegar?idNorma=1147774\&idVersion=2020-12-10\&idParte=. 
Macarena Bustamante y Roberto Astaburuaga: La protección de la libertad de culto en tiempos de pandemia: la jurisprudencia de la corte de apelaciones de concepción. Comentario a las sentencias 7800-2020, 9692-2020 y $11125-2020$.

comunas en Fase 2, puedan celebrarse ritos religiosos. Lo anterior constituye, nuevamente, una discriminación arbitraria, ya que no existe una fundamentación suficiente para no establecer las mismas medidas que a otras actividades que, por ser consideradas "fundamentales", gozan de permisos especiales para ser realizadas en lapsos de hasta 4 horas. Con todo, y siendo la libertad de culto un derecho de carácter esencial, los creyentes están en los hechos, impedidos de ejercerlo siquiera por una hora, durante dichas fases, lo cual es manifiestamente ilegal y contrario a la garantía constitucional en el artículo $19 \mathrm{~N}^{\circ} 6$ de nuestra Constitución.

Es aquí donde se revela la gran importancia de la sentencia Rol N¹1125-2020 de la Corte de Apelaciones de Concepción, ya que constituye un precedente ante nuevas violaciones que puedan ocurrir, especialmente para los ciudadanos que se encuentren en fase 1 o 2 y que deseen ejercer su derecho a la libertad de culto. El mérito de la sentencia radica en que la Corte acoge la solicitud de protección de este derecho, reconociendo su capital importancia y que la orden de permitir su ejercicio no significa entrar a cuestionar los motivos del Poder Ejecutivo en la adopción de políticas públicas para enfrentar el contagio y propagación del Covid-19, sino de restablecer el derecho contra una medida específica inconstitucional. Esperamos que los Tribunales Superiores de Justicia resuelvan tal como lo hizo la Corte de Concepción, haciendo las distinciones sanas y necesarias que permiten la armonía y equilibrio entre el control de la pandemia a través de normas sanitarias dictadas en un estado de excepción constitucional con el ejercicio de la libertad de culto sujeto a tales restricciones, mas nunca suspendido.

\section{CONCLUSIONES}

En tiempo de pandemia, ciertas medidas dictadas por la Autoridad Sanitaria han significado la vulneración de la libertad de culto de quienes intentaban acudir a los templos 
Macarena Bustamante y Roberto Astaburuaga: La protección de la libertad de culto en tiempos de pandemia: la jurisprudencia de la corte de apelaciones de concepción. Comentario a las sentencias 7800-2020, 9692-2020 y $11125-2020$.

a rezar o celebrar culto. Solicitada la intervención de la Corte de Apelaciones de Concepción, esta fue modificando su criterio tanto en lo relativo tanto a su competencia para conocer dichos actos, como en las razones para fundar sus decisiones de fondo sobre la materia.

Todo acto de la autoridad que tenga por objeto la prohibición de las actividades religiosas es ilegal y arbitrario. En primer lugar, son ilegales por contravenir expresamente normas consagradas en tratados internacionales sobre derechos humanos, ratificados por Chile y actualmente vigentes, y porque perturban el legítimo ejercicio de la libertad religiosa, consagrado en el numeral $6^{\circ}$ del artículo 19 de nuestra Constitución Política.

En segundo lugar, son arbitrarias porque la racionalidad y proporcionalidad de las medidas no cumplen con los requisitos de idoneidad, necesidad y estricta proporcionalidad. Las medidas serán idóneas si es que el medio elegido es apto para conseguir el fin que la justifica; serán necesarias, si el medio elegido es el menos incisivo sobre los intereses privados, y serán estrictamente proporcionales, si el logro del fin público compensa el sacrificio del interés privado, requisitos que las resoluciones prohibitivas citadas en este comentario, no cumplían en la especie, transformándolos en arbitrarios y desproporcionados en relación con el fin pretendido.

La importancia de la jurisprudencia analizada, y sobre todo de la sentencia Rol $\mathrm{N}^{\circ}$ 11125-2020, radica en otorgar una protección directa contra medidas particulares dictadas por la autoridad que vulneran la libertad de culto, ordenando el restablecimiento del derecho, y no excusándose de conocer tales materias, por estimar que son propias del Poder Ejecutivo en la administración del control de la pandemia, y por ello ajenas su conocimiento y decisión.

Los casos recién comentados permiten apreciar la labor de los Tribunales Superiores de Justicia, y su deber de proteger los derechos fundamentales - precisamente aquellos que emanan de su más honda naturaleza -, de los actos ilegales y arbitrarios que puede dictar la 
Macarena Bustamante y Roberto Astaburuaga: La protección de la libertad de culto en tiempos de pandemia: la jurisprudencia de la corte de apelaciones de concepción. Comentario a las sentencias 7800-2020, 9692-2020 y $11125-2020$.

Autoridad Sanitaria. De no hacerlo, existe el riesgo de no poder fiscalizar e impugnar los actos del Estado, dando con ello ocasión a la proliferación de arbitrariedades que lleven a olvidar el respeto y resguardo debidos a los derechos fundamentales de las personas. Los hechos que dieron origen a estos fallos permiten revisar las políticas públicas sanitarias adoptadas durante la pandemia, particularmente en relación al ejercicio de la libertad religiosa, donde el Estado pareciera haberse arrogado la facultad de determinar cuáles servicios o actividades serían esenciales y cuáles no. Ciertamente, el ejercicio legítimo de la libertad religiosa, derecho natural y anterior al Estado, tiene un carácter predominante para la vida humana, por lo que no puede ser rebajada al nivel de otro tipo de actividades consideradas prescindibles.

\section{BIBLIOGRAFÍA}

\section{Normas}

- Ministerio de Salud (Chile), Resolución 341 Exenta: Dispone medidas sanitarias que indica por brote de Covid-19, Santiago, Chile, 2020, 7 p.

- Ministerio de Salud (Chile), Resolución 349 Exenta: Dispone medidas sanitarias que indica por brote de Covid-19, Santiago, Chile, 2020, 3 p.

- Ministerio de Salud (Chile), Resolución 203 Exenta: Dispone medidas sanitarias que indica por brote de Covid-19, Santiago, Chile, 2020, 6 p.

- Ministerio de Salud (Chile), Resolución Exenta 591: Dispone medidas sanitarias que indica por brote de Covid-19, Santiago, Chile, 2020, 23 p.

- Ministerio del Interior y Seguridad Pública (Chile), Decreto Supremo 104: Declara Estado de Excepción Constitucional de Catástrofe, por calamidad pública, en el territorio de Chile, Santiago, Chile, 2020, 6 p.

- Secretaría Regional Ministerial de Salud de la XVI Región del Ñuble (Chile), Resolución Exenta 8804: Establece restricciones que indica, Chillán, Chile, 2020, 3 p. 
- Secretaría Regional Ministerial de Salud de la VII Región del Maule (Chile), Resolución Exenta 726: Decreta prohibición de realización de aforo y eventos religiosos en el contexto de alerta sanitaria decretada por el Ministerio de Salud por brote de Covid -19, Talca, Chile, 2020, 3 p.

- Secretaría Regional Ministerial de Salud de la VI Región del Libertador General Bernardo O’Higgins (Chile), Resolución Exenta 988: Establece límite de asistentes en actividades ciudadanas en espacios abiertos y cerrados, Rancagua, Chile, 2020, 3 p.

- Secretaría Regional Ministerial de Salud de la XI Región del Aysén (Chile), Resolución Exenta 232: Prohíbe actividades que indica, Coyhaique, Chile, 2020, 2 p.

- Secretaría Regional Ministerial de Salud de la VIII Región del Bío Bio (Chile), Resolución Exenta 1094, Concepción, Chile, 2020, 3 p.

- Secretaría Regional Ministerial de Salud de la VIII Región del Bío Bio (Chile), Resolución Exenta 1509, Concepción, Chile, 2020, 4 p.

- Secretaría Regional Ministerial de Salud de la VIII Región del Bío Bio (Chile), Resolución Exenta 1529, Concepción, Chile, 2020, 3 p. Leyes

- Ley N¹9.638. Diario Oficial de la República de Chile, Santiago, Chile, 14 de Octubre de 1999.

\section{Tratados Internacionales}

- Convención Americana sobre Derechos Humanos (Pacto de San José de Costa Rica), San José, Costa Rica, 7 al 22 de noviembre de 1969. Ratificado por Chile el 8 de octubre de 1990.

- Pacto Internacional de Derechos Civiles y Políticos, 16 de diciembre de 1966. Ratificado por Chile el 27 de mayo de 1992.

- Declaración Universal de los Derechos del Hombre y del Ciudadano, 26 de agosto de 1789.

- Convenio Europeo para la Protección de los Derechos Humanos y de las Libertades Fundamentales, 4 de noviembre de 1950. 
Macarena Bustamante y Roberto Astaburuaga: La protección de la libertad de culto en tiempos de pandemia: la jurisprudencia de la corte de apelaciones de concepción. Comentario a las sentencias 7800-2020, 9692-2020 y $11125-2020$.

\section{Sentencias}

- Ilustrísima Corte de Apelaciones de Concepción, Rol N. 7800-2020, sentencia con fecha 7 de abril de 2020.

- Excelentísima Corte Suprema, Rol Nº 42.853-2020, sentencia con fecha 24 de abril de 2020.

- $\quad$ Ilustrísima Corte de Apelaciones de Concepción, Rol N.9692-2020, sentencia con fecha 22 de julio de 2020.

- Ilustrísima Corte de Apelaciones de Concepción, Rol N. 11125-2020, sentencia con fecha 23 de julio de 2020.

- Corte Interamericana de Derechos Humanos, Olmedo Bustos y otros versus Chile, sentencia con fecha 5 de febrero de 2001

- Comité de Derechos Humanos. Observación General N²2: Derecho a la libertad de pensamiento, de conciencia y de religión (art. 18), 1993.

- Comité de Derechos Humanos. Observación General N²2: Derecho a la libertad de pensamiento, de conciencia y de religión (artículo 18), 1993.

- $\quad$ Tribunal Constitucional, Rol N²53-88, sentencia con fecha 5 de abril de 1988.

- Tribunal Constitucional, Rol N²19-95, sentencia con fecha 31 de julio de 1995.

- Tribunal Constitucional, Rol N 1307-09, sentencia con fecha 21 de enero de 2011.

- Tribunal Constitucional, Rol N 1448-09, sentencia con fecha 7 de septiembre de 2010.

- Tribunal Constitucional, Rol N 1584-09, sentencia con fecha 17 de junio de 2010.

- Sentencia del Tribunal Constitucional Español 177/1996, de 11 de noviembre.

\section{Documentos}

- AA.VV., El principio de proporcionalidad en el Estado Constitucional (coord. Miguel Carbonell), Ministerio de Justicia y Derechos Humanos de Colombia, Colombia, 2007.

- ALEXY, Robert, Teoría de los derechos fundamentales, Centro de Estudios Constitucionales, Madrid, 1997. 
- ARNOLD, Reiner, MARTínEZ ESTAY, José Ignacio et al, “El principio de proporcionalidad en la jurisprudencia constitucional”, Estudios constitucionales, vol.10, №, Santiago, 2012.

- CARLON RUIZ, Matilde, "El principio de proporcionalidad", en Los principios jurídicos del derecho administrativo (dir. Juan Alfonso Santamaría Pastor), 2010, 203-230 pp.

- DE LA FUENTE CASTRO, Osvaldo. Control judicial de la resolución de calificación ambiental, Santiago, 2012.

- EVANS DE LA CUADRA, Enrique, Los derechos constitucionales, Tomo II, Editorial Jurídica de Chile, Santiago, 2004.

- NOGUEIRA ALCALÁ, Humberto, Derechos fundamentales y garantías constitucionales, Tomo II, Editorial Librotecnia, Santiago, 2010.

- NOGUEIRA ALCALÁ, Humberto, La libertad de conciencia, la manifestación de creencias y la libertad de culto en el ordenamiento jurídico chileno, lus et Praxis, Talca, 2006.

- PRIORA, Juan Carlos, Libertad de conciencia, libertad religiosa, libertad de culto y tolerancia en el contexto de los derechos humanos (perspectiva histórico-bíblica), Enfoques XIV, 2002.

- Revista de Derecho y Jurisprudencia, 1983, T.80, N²,2.5, pp. 40-45.

- Revista de Derecho y Jurisprudencia., 1985, T. 82, № 2, 2.5, pp. 151-157.

- SARMIENTO, Daniel, El principio de proporcionalidad en el Derecho Administrativo. Un análisis jurídico desde el Derecho Español, U. Externado de Colombia, Colombia, 2007. 